Indo. J. Chem. Res., 2019, 7(1), 86 -91

\title{
EXTRACTION, FRACTIONATION, AND ANTIOXIDANT EXAMINATION OF POLYFLORAL HONEY ORIGINATED FROM BONE PREFECTURE SOUTH SULAWESI PROVINCE
}

\author{
Fredryk Mandey*, Endah Handayani, Wahyuni Eka Nanda, Alfian Noor \\ ${ }^{I}$ Department of Chemistry, Faculty of Mathematics and Natural Sciences, Hasanuddin University \\ Jl. Perintis Kemerdekaan km 10, Makassar-90245, Indonesia \\ *Corresponding author, e-mail: fmandey65@gmail.com
}

Received: Marc. 2019 Published: Jul. 2019

\begin{abstract}
The aim of this research are to isolate, identify, and test the antioxidant activity of both extract and fractions of polyfloral honey originated from Bone regency, South Sulawesi. The results showed that methanol crude extract phytochemically consisted of flavonoid, tannin, saponin, steroid, and alkaloid with $\mathrm{IC}_{50}$ value of $\mathrm{DPPH}(1,1$ diphenyl-2-picrylhydrazyl) method of $683,153 \mu \mathrm{g} / \mathrm{mL}$. The DCM extract gave positive results for tannin, steroid and alkaloid with $\mathrm{IC}_{50}$ value of $701,743 \mu \mathrm{g} / \mathrm{mL}$. The $\mathrm{n}$-hexane extract positively contained tannin and alkaloid with $\mathrm{IC}_{50}$ value of $1709,536 \mu \mathrm{g} / \mathrm{Ml}$. The water extract positevely contains tannin, saponin steroid, alkaloid with $\mathrm{IC}_{50}$ value of $1698,345 \mu \mathrm{g} / \mathrm{mL}$. Pure honey contains all group of compounds tested with $\mathrm{IC}_{50}$ value 2826,471 $\mu \mathrm{g} / \mathrm{mL}$. This showed extracts and sample have weak antioxidant activity.
\end{abstract}

Keywords: Polyfloral honey, fractionation, phytochemistry, antioxidant

\section{INTRODUCTION}

Free radical, a reactive species that occur as a cause of non-paired electron, can be found in the metabolism process in human bodies. Those very reactive electrons tried to stabilize itself by reacting with the environment in order to find a lone-pair electron. This reaction can occur simultaneously and continuously until the stable condition is achieved. However, this process must be terminated as fast as possible to prevent degenerative disease, such as: cancer, hearth failure, and cataract. An antioxidant is needed to accelerate the stabilization of those free-radical, which can be synthesised in-vivo, or being administered in-vitro (Kikuzaki et al., 2002; Sibuea, 2003).

An Antioxidant is a constituent that has an ability to inhibit super-oxidation reaction that occurs in the human body and forms a species that can stabilize the free radical. Human bodies have various type of antioxidant, such as: superoxide dismutase enzyme, glutathione, and catalase enzyme that can stabilize the free radical. However, an antioxidant also can be produced in-vitro from natural product. One type of natural product that can be utilized as a source of antioxidant is honey (Escuredo et al., 2013; Moniruzzaman et al., 2013).
Honey, a typical sweet viscous liquid originated from the floral nectars, can be divided into two type based on the sources of its nectar, e.g., monofloral honey and polyfloral honey. The initial honey is produced from single type of floral; while the later one, sometimes called as forest honey, is from the nectar of various floras (Sutanto, 2007).

There are several nutritional constituents of honey that can function as antioxidant agents, for instance: Vitamin C, organic acid, phenolic acid, flavonoids, and $\beta$-carotene (Gheldof, 2002). There are lots of flavonoids and phenolic compounds have been isolated and structurally determined from honey (Vulic et al., 2015; Ramanauskiene et al., 2012; Alvarez-Suarez et al., 2014). The most common methods to determine the presence of antioxidant in honey is the DPPH method, which uses 1,1-diphenyl-2picrylhydrazyl that can trap the excess of free radical. This method is effective and efficient due to several advantages such as, is able to capture high concentration of free radicals, uses less amount of sample, happens at room temperature, and only uses the simple standard UV-Visible spectrophotometry to determine the results (Salamah and Widyasari, 2015).

This research is aimed to fractionate the polyfloral honey into several fraction based on 
the decreasing of polarity from polar to nonpolar; and to evaluate further the efficacy of those fractions as an antioxidant agents.

\section{METHODOLOGY}

\section{Instruments}

Standard chemical instrument were used in this research like rotary evaporator (Buchi), and UV-Visible spectrometer (Spectronic-20D+; Shimadzu).

\section{Materials}

Polyfloral honey samples were taken from the forest area nearby Sadar Village, Bone Regency, South Sulawesi Province, and kept in a sealed dried bottle jar. The samples were then freeze-drying after taken to avoid the direct oxidation of air.

\section{Experimental Procedure \\ Extraction and fractionation}

Approximately 78 grams of dried polyfloral honey sample were firstly macerated with 250 $\mathrm{mL}$ of methanol p.a for 48 hours. Afterwords, the filtrate was then separated from the residue. This protocol were repeated 3 (three) times and all of the filtrate was combined and evaporate under reduced pressure to obtain crude methanol extract.

\section{Fractionation of the crude extract}

Approximately 2 grams of the methanol crude extract of polyfloral honey were put in a $50 \mathrm{~mL}$ bottle and $30 \mathrm{~mL}$ distilled water were added into the bottle with further shaking with a sonicator for about 30 minutes. After kept the bottle stands for 30 minutes and the solution was decanted to obtain an aqueous fraction of the extract polyfloral honey.

The above protocol was repeated with underwent the solvent of dichloromethane and nhexane to results the fraction of dichloromethane and $n$-hexane. All of the fractions was then dried under reduced pressure to obtain the dried materials which were kept in small sample vial to be used in the antioxidant test.

\section{Phytochemistry evaluation}

Prior to the antioxidant test, under a standard procedure proposed by Tiwari et al., a phytochemistry evaluation, to all fractions as well as the crude methanol extract and the original sample, were done in order to known the major class of secondary metabolites that consist in the sample, crude extract, and fractions of the polyfloral honey.

\section{Antioxidant test \\ Preparation of DPPH 0,4 mM solution}

Approximately 0.015 grams of DPPH was dissolved with $25 \mathrm{~mL}$ of methanol and transferred into a $100 \mathrm{~mL}$ volumetric flask. The remaining methanol were then added until it reaching the precise volume of the volumetric flask in order to obtain $0.4000 \mathrm{mM}$ of DPPH solution

\section{Preparation of stock solution of ascorbic acid $500 \mathrm{ppm}$ and $5 \mathrm{ppm}$}

Precisely $0.500 \mathrm{~g}$ of ascorbic acid were weighed and transferred into a $10 \mathrm{~mL}$ volumetric flask, and further added with methanol p.a until the precise volume to obtain $500 \mathrm{ppm}$ of ascorbic acid solution. From the stock solution $0.1 \mathrm{~mL}$ were taken using a micro pipette and transferred into a $10 \mathrm{~mL}$ volumetric flask following by addition of methanol p.a until the limit volume to get $5 \mathrm{ppm}$ of ascorbic acid solution

\section{Preparation of $500 \mathrm{ppm}$ solution of aqueous fraction}

An aqueous extract of polyfloral honey were precisely weighed as many as $0.3329 \mathrm{~g}$ and transferred into a $25 \mathrm{~mL}$ Erlenmeyer flask and dissolved with $10.1 \mathrm{~mL}$ of methanol to result in $33,000 \mathrm{ppm}$ of a stock solution. From the stock solution $0.15 \mathrm{~mL}$ were then taken and transferred into a $10 \mathrm{~mL}$ volumetric flask and added a methanol solvent up to the volume limit to obtain $500 \mathrm{ppm}$ of methanol extract solution.

\section{Preparation of $500 \quad \mathrm{ppm}$ solution of dichloromethane fraction}

Precisely $0.0682 \mathrm{gr}$ of dichloromethane fraction were transferred into a $25 \mathrm{~mL}$ Erlenmeyer flask and dissolved with $10.2 \mathrm{~mL}$ of methanol p.a to obtain a $6,000 \mathrm{ppm}$ stock solution. From the stock solution, $0.83 \mathrm{~mL}$ were pipette into a $10 \mathrm{~mL}$ volumetric flask using micro pipette with further addition of methanol p.a solvent up to the limit volume of $10 \mathrm{~mL}$ to obtain $500 \mathrm{ppm}$ solution of DCM fraction. 
Preparation of $500 \mathrm{ppm}$ solution of n-hexane fraction

Precisely $0.0058 \mathrm{~g}$ of $\mathrm{n}$-hexane fraction were put into a $25 \mathrm{~mL}$ Erlenmeyer flask and dissolved with $1 \mathrm{~mL}$ of DMSO with a further addition of $11.6 \mathrm{~mL}$ of methanol p.a to provide $500 \mathrm{ppm}$ of the n-hexane fraction solution. The methanol extract of polyfloral honey approximately $1.016 \mathrm{~g}$ were dissolved with 10.2 $\mathrm{mL}$ in a $25 \mathrm{~mL}$ Erlenmeyer flask to obtain a stock solution with a concentration of 100,000 ppm. From the stock solution $0.05 \mathrm{~mL}$ were then taken and transferred to a $10 \mathrm{~mL}$ volumetric flask and added a methanol solvent up to the volume limit to obtain $500 \mathrm{ppm}$ of the methanol extract. until the test tube has a total volume of $5 \mathrm{~mL}$. All test tubes were then incubated at dark with room temperature for about 30 minutes, and all solutions were measured using a UV-Vis spectrometer at a maximum wavelength of 515 nm.

\section{Determination of antioxidant activities of polyfloral sample and fractions}

From the solution of $500 \mathrm{ppm}$ aqueous fraction $0.1 \mathrm{~mL}, 0.2 \mathrm{~mL}, 0.4 \mathrm{~mL}, 0.8 \mathrm{~mL}$, and $1.6 \mathrm{~mL}$ were taken by a micro pipette and filledin to the 5 (five) labelled test tube, with the further addition of $1 \mathrm{~mL}$ of $0.4 \mathrm{mM} \mathrm{DPPH}$.

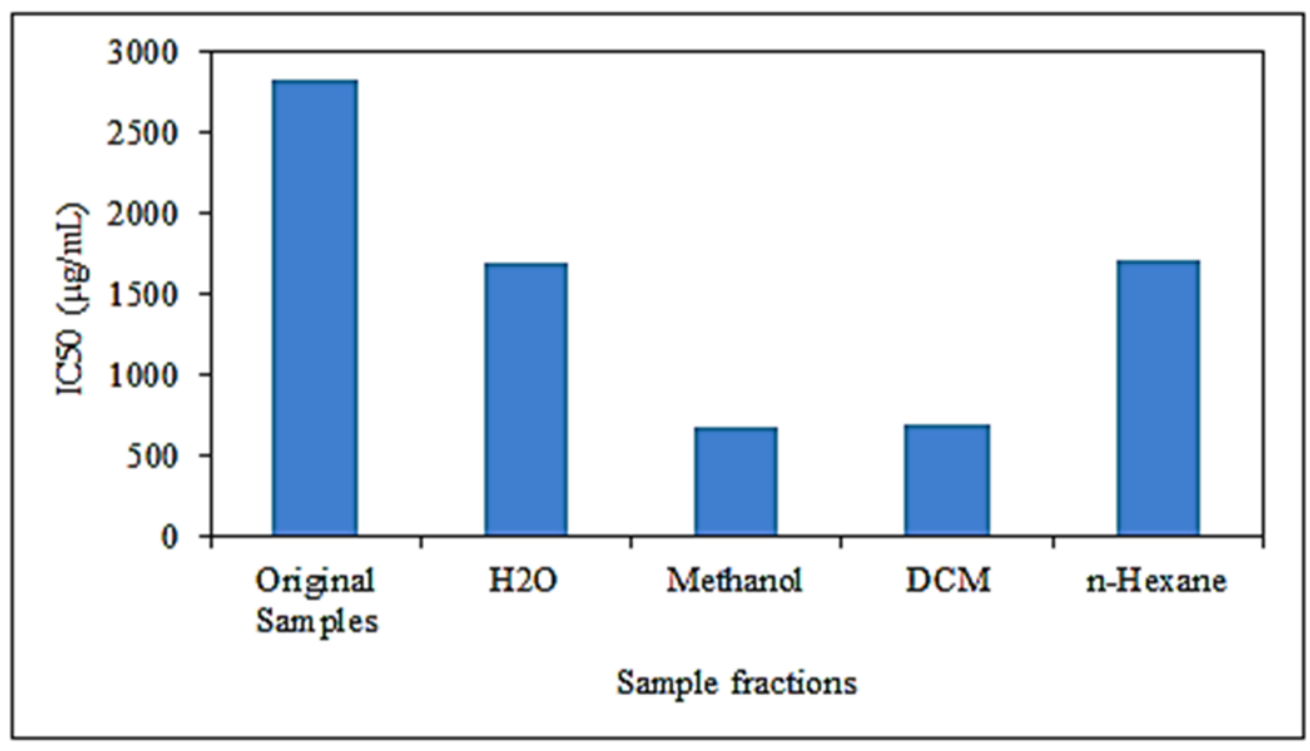

Figure 1. Calculated $\mathrm{IC}_{50}$ of the original samples and fraction of polyflora honey

\section{Preparation of $500 \mathrm{ppm}$ polyfloral honey sample}

An empty and pre-weighted vial were fill-in with $0.005 \mathrm{gr}$ of honey sample and adding about $10 \mathrm{~mL}$ methanol p.a, homogenized, and kept stored before of being used in the experiment.

\section{Determination of antioxidant activities of ascorbic acid}

The antioxidant activity test of the reference ascorbic acid was carried out by firstly pipetting $0.25 ; 0.5 ; 1 ; 2$; and $4 \mathrm{~mL}$ of the 5 ppm solution of ascorbic acid that has already been prepared and transferred into 5 (five) different test tubes. Each test tube was filled with $1 \mathrm{~mL}$ of DPPH 0.4 $\mathrm{mM}$, and further added with methanol p.a solvent
All test tubes were then added with methanol p.a up to reach the total volume of 5 $\mathrm{mL}$ to obtain $10,20,40,80$, and $160 \mathrm{ppm}$. All solutions were incubated in the dark, at room temperature, for 30 minutes and measured with $\mathrm{UV}-\mathrm{V}$ is spectrometer at a maximum wavelength of $515 \mathrm{~nm}$.

\section{RESULTS AND DISCUSSION}

The investigation consisted of 3 (three) major parts, e.g., fractionation, phytochemical test, and antioxidant assay. Crude extracts from extraction, underwent a maceration, about $2 \mathrm{~g}$ of extracts were consecutively fractionated with water, dichloromethane, and n-hexane to obtain 


\section{Fredryk Mandey dkk. / Indo. J. Chem. Res., 2019, 7(1), 86-91}

$0.33,0.06,0.005 \mathrm{~g}$ of each fraction. A small part of the fraction was taken for the further phytochemical test used Tiwari et al., 2011 protocol to give a results described in Table 1. (three) major constituents; tannin, steroid, and alkaloid; while n-hexane only have tannin and alkaloid.

Table 1. Phytochemical test results of polyfloral honey extract, fractions, original sample

\begin{tabular}{|c|c|c|c|c|c|}
\hline \multirow{2}{*}{ Sample type } & \multicolumn{5}{|c|}{ Observation results } \\
\hline & Flavonoid & Tannin & Saponin & Steroid & Alkaloid \\
\hline $\begin{array}{l}\text { Original honey } \\
\text { sample }\end{array}$ & + & + & + & + & + \\
\hline Aqueous fraction & - & + & + & + & + \\
\hline DCM fraction & - & + & - & + & + \\
\hline n-Hexane fraction & - & + & - & - & + \\
\hline Methanol extract & + & + & + & + & + \\
\hline
\end{tabular}

The phytochemical assessment results clearly show that both original polyfloral honey sample and methanol crude extract contains all major constituents of secondary metabolites, e.g., flavonoid, tannin, saponin, steroid, and alkaloid. This is due to the fact that polyfloral honey mostly contains of all major class of secondary methabolites (Stevenson et al., 2017), furthermore, in case of the methanolic extract, as a cause of the ability of methanol to destroy the cell wall make it possible to take almost all of the secondary metabolites contains in the sample (Eloff, 1998).

\section{Antioxidant test}

An antioxidant test (Kedare and Singh, 2011) were carried out toward the original sample, methanol extract, and all fractions, e.g., aqueous, DCM, and n-hexane extracts. Ascorbic acid was use as a reference for positive standard antioxidant. The results are shown in Table 2 .

Seems that DCM is the fraction that has the highest antioxidant activity of $12.18 \%$ in the concentration of $160 \mu \mathrm{g} / \mathrm{mL}$ whereas methanol, $\mathrm{n}$-hexane, aqueous, and the original sample of polyfloral honey have the concentration of 10.82 , $6.59,5.45$, and $4.65 \%$ consecutively.

Table 2. Antioxidant test results

\begin{tabular}{ccccccc}
\hline No & $\begin{array}{c}\text { Concentration } \\
(\mu \mathrm{g} / \mathrm{mL})\end{array}$ & \multicolumn{5}{c}{$\begin{array}{c}\text { Antioxidant activities (\%) } \\
\text { Fraction }\end{array}$} \\
& & $\mathrm{MeOH}^{*}$ & $\mathrm{DCM}$ & $\mathrm{n}-\mathrm{Hexane}$ & Aqueous & Polyfloral \\
& & 0,24 & 1,41 & 2,42 & 1,14 & 2,03 \\
\hline 1 & 10 & 0,47 & 2,34 & 2,64 & 1,36 & 2,33 \\
2 & 20 & 1,88 & 3,98 & 3,30 & 1,82 & 2,62 \\
3 & 40 & 4,94 & 6,32 & 4,40 & 2,95 & 3,49 \\
4 & 80 & 10,82 & 12,18 & 6,59 & 5,45 & 4,65 \\
5 & 160 & \multicolumn{6}{c}{} \\
\hline
\end{tabular}

*crude methanol extracts

Other fraction, like aqueous, dichloromethane, and n-hexane has a variability in secondary metabolites contentmend is due to the diffrerence of the polarity which limiting the ability to take the constituents which has different degree of polarity. Overall results are, both original sample and methanol extract contains all of the major secondary metabolites; and aqueous fraction consist of all except flavonoids. Moreover, dichloromethane has 3
Based on the data it can be stated that the percentage of inhibition was in linear correlation with concentration. The increasing of concentration will also increase the inhibition percentage. Based on the antioxidant data of the inhibition percentage we calculated the $\mathrm{IC}_{50}$ values, described in Figure 1, and resulted in the values of $683.153,701.743,1698.345,1709.536$, and $2826.471 \mu \mathrm{g} / \mathrm{mL}$ for methanol extract, DCM fraction, aqueous, n-hexane, and original 


\section{Fredryk Mandey dkk. / Indo. J. Chem. Res., 2019, 7(1), 86-91}

polyfloral honey samples respectively. The $\mathrm{IC}_{50}$ values are in reverse correlation with the percentage activity, the higher the antioxidant activity of the sample the lower the values of its $\mathrm{IC}_{50}$ (Molyneaux, 2004). The above data also show some interesting trends based on the solvent polarity. The original sample of polyfloral honey has an $\mathrm{IC}_{50}$ value of 2826.471 which is the highest, but relates to the lowest activity. The $\mathrm{IC}_{50}$ value then went further down to 1709.536 and $683.153 \mu \mathrm{g} / \mathrm{mL}$ for aqueous and methanol fractions; then increasing up to 701.743 and $1698.345 \mu \mathrm{g} / \mathrm{mL}$ for DCM and $\mathrm{n}$ Hexane fractions. So, it was clearly shown a correlation of the value and the activity which is the higher the values the least the activity does.

These trends perhaps due to the molecular content of the original sample, extract and fractions of the polyfloral honey. The phytochemical test (Tiwari et al., 2011) in Table 1 shows that the original sample and methanol extract predominantly have all of the major secondary metabolites constituents (flavonoid, tannin, saponin, steroid, and alkaloid), while the aqueous has all constituents except flavonoid. Moreover, DCM and n-Hexane fraction only have fewer constituents content, e.g., tannin, steroid, and alkaloid. As a reference ascorbic acid also were tested for its antioxidant activities and gave results as described in Table 3.

Table 3 Ascorbic acid test results

\begin{tabular}{cccc}
\hline No & $\begin{array}{c}\text { Concentration } \\
(\mu \mathrm{g} / \mathrm{mL})\end{array}$ & $\begin{array}{c}\text { Antioxidant } \\
\text { activity }(\%)\end{array}$ & $\begin{array}{c}\mathrm{IC}_{50} \\
(\mu \mathrm{g} / \mathrm{mL})\end{array}$ \\
\hline 1 & 0,25 & 27,10 & 2,597 \\
2 & 0,5 & 30,70 & \\
3 & 1 & 35,25 & \\
4 & 2 & 42,69 & \\
5 & 4 & 64,03 & \\
\hline
\end{tabular}

The values of $\mathrm{IC}_{50}$ of ascorbic acid which is $2.597 \mu \mathrm{g} / \mathrm{mL}$ at the lowest concentration of 0.25 $\mu \mathrm{g} / \mathrm{mL}$ shown a very strong antioxidant activity. According to Molyneaux, 2004., a constituent can be categorized as a very strong antioxidant if the $\mathrm{IC}_{50}<50 \mu \mathrm{g} / \mathrm{mL}$; strong if the $\mathrm{IC}_{50}$ in between 50 to $100 \mu \mathrm{g} / \mathrm{mL}$; medium if the $\mathrm{IC}_{50}$ values 100 to $150 \mu \mathrm{g} / \mathrm{mL}$; and weak if the $\mathrm{IC}_{50}$ value is in between 150 to $200 \mu \mathrm{g} / \mathrm{mL}$.

\section{CONCLUSIONS}

The research has examined the antioxidant activity of the polyfloral honey and its fraction using the DPPH method with low activities with the of $\mathrm{IC}_{50}$ values of $683.153 ; 701.743$; 1709.536; and $1698.345 \mu \mathrm{g} / \mathrm{mL}$ for methanol extract, DCM fraction, n-Hexane fraction, and aqueous fraction in compared to the original sample with the values $2826.471 \mu \mathrm{g} / \mathrm{mL}$. The phytochemical test also clearly shown that tannin and alkaloid became the predominant constituents because it was found in all sample test and flavonoid became the least because only be found in the original sample and the methanol extract.

\section{REFERENCES}

Kikuzaki, H., Hisamoto, M., Hirose, K., Akiyama, K., Taniguchi, H., 2002, Antioxidants Properties of Ferulic Acid and Its Related Compounds, J. Agric. Food Chem., 50, 2161-2168.

Sibuea, P., 2003, Antioksidan Senyawa Ajaib Penangkal Penuaan Dini, Sinar Harapan, Jogyakarta

Suranto, A., 2007, Terapi Madu, Penebar Plus, Jakarta.

Escuredo, O., Miguez, M., Fernandez-Gonzalez, M., Seijo, M.C., 2013, Nutritional values and antioxidant activity of honey produced in European Atlantic area, Food Chem., $138,851-856$

Moniruzzaman, M., Sulaiman, S.A., Khalil, M.I., Gan, S.H., 2013, Evaluation of physicochemical and antioxidant properties of sourwood and other Malaysian honeys: a coparison with Manuka honey, Chem. Cent. J., 7, 138

Gheldof, N., Engeseth, N.J., 2002, Antioxidant Capacity of Honey from Various Sources Based on Determination of Oxygen Radical Absorbance Capacity and Inhibition of invitro Lipoprotein Oxidant in Human Serum Samples, J. Agric. Food Chem., 50 (10), 3050-3055.

Vulic, J., Brunet, J., Cetkovic, G., Djilas, S., Saponjak, T., 2015, Antioxidant and Censorial Properties of Polyfloral Honey with Dried Apricots After One Year of Storage, J. Chem., 1-7 
Ramanauskiene, K., Stelmakiene, A., Briedis, V., Ivanauskas, L., Jakstas, V., 2012, The qualitative analysis of biologically active compounds in Lithuanian honey, Food Chem., 132, 1544-1548

Alvarez-Suarez, J.M., Gasparrini, M., ForbesHernadez, T.Y., Mazzoni, L., Giampiri, F., 2014, The composition and biological activity of honey: A focus on Manuka honey, Foods, 3(3), 420-432.

Salamah, N., Widyasari, E., 2015, Aktivitas Antioksidan Ekstrak Metanol Daun Kelengkeng (Euphoria (L) Steud Dengan Metode Pengikatan Radikal 2,2-difenil-1pikril-hidrazil, Pharmaciana, 5(1), 25-34.

Tiwari, P., Kumar, B., Kaur, M., Kaur, G., Kaur, H., 2011, Phytochemical Screening and Extraction : A Review, Inter. Pharma. Sciencia, 1(1), 98-106.
Kedare, S.B., Singh, R.P., 2011, Genesis and Development of DPPH Method of Antioxidant Assay, J. Food Sci. Technol., 48(4), 412-422.

Colegate, S.M., Molyneaux, R.J., 2007, Bioactive Natural Products : Detection, Isolation, and Structural Determination, $2^{\text {nd }}$, CRC Press.

Stevenson, P.C., Nicholson, S.W., Wright, G.A., 2017, Plant Secondary Metabolites in nectar: impacts on pollinators and ecological functions, Funct. Ecol., 31, 6575.

Eloff, N.J., 1998, Which extractant should be used for the screening and isolation of antimicrobial components from plants?, $J$. Ethnopharmacol., 60, 1-8. 